\title{
TRATAMENTO TÉRMICO DE RESSOLUBILIZAÇÃO EM UMA LIGA DE ALUMÍNIO 7475-T7351*
}

\author{
Saulo Brinco Diniz ${ }^{1}$ \\ Andersan dos Santos Paula ${ }^{2}$ \\ Luiz Paulo Mendonça Brandão ${ }^{3}$
}

\section{Resumo}

O presente trabalho buscou explorar a influência de um tratamento térmico de ressolubilização, realizados com distintos tempos (70, 80 e 90 minutos) a uma temperatura de $510^{\circ} \mathrm{C}$, na microestrutura e na dureza de uma liga de alumínio 7475T7351. Para verificar a influência destes tratamentos térmicos foram utilizados um durômetro (fabricante EMCOTEST, modelo Duravision 300) e um microscópio óptico (Olympus, modelo GX51). Após os resultados obtidos, pode-se evidenciar que a liga de alumínio em estudo sofre um envelhecimento natural (a temperatura ambiente), e dentre os tempos de encharque estudados, 70 minutos é o tempo que possivelmente obtém-se a maior ressolubilização dos precipitados.

Palavras-chave: Liga de alumínio 7475-T7351; Tratamento térmico de ressolubilização; Microestrutura; Dureza Vickers.

\section{RESOLUTION HEAT TREATMENT IN AN 7475-T7351 ALUMINUM ALLOY}

\begin{abstract}
This study aimed to explore the influence of a resolution heat treatment (with different soaking times, 70,80 and 90 minutes, at $510^{\circ} \mathrm{C}$ ), on microstructure and hardness of an 7475-T7351 aluminum alloy. To check the influence of these heat treatments, were used Vickers hardness measurements (EMCOTEST, DuraVision 300) and optical microscope analysis (Olympus, GX51). After the results, concluded that the 7475-T7351 aluminum alloy after resolution heat treatment undergoes a natural aging (room temperature), and the soaking time of 70 minutes, possibly get to most of the precipitates resolubilization.
\end{abstract}

Keywords: 7475-T7351 aluminum alloy; Resolution heat treatment; Microstructure; Hardness Vickers.

1 Eng. Metalurgista, M.Sc., Doutorando em Ciência dos Materiais, Instituto Militar de Engenharia, Rio de Janeiro; Professor DI - 1, Centro Federal de Educação Tecnológica Celso Suckow da Fonseca, Angra dos Reis, RJ, Brasil. saulo_brinco@hotmail.com

2 Engenheira Metalurgista, D.Sc., Professora Adjunta, Instituto Militar de Engenharia, Rio de Janeiro, RJ, Brasil; e orientadora credenciada no PPGEM/UFF, Volta Redonda, RJ, Brasil.

3 Engenheiro Metalurgista, D.Sc., Professor Adjunto, Instituto Militar de Engenharia, Rio de Janeiro, RJ, Brasil. 


\section{INTRODUÇÃO}

Tratamentos térmicos em ligas metálicas são muito utilizados devido uma enorme gama de resultados possíveis diferentes obtidos na microestrutura resultante e consequentemente nas propriedades mecânicas dos materiais tratados termicamente. Como objetivo dos tratamentos térmicos, pode-se destacar a transformação de fase, a recristalização de uma matriz encruada devido ao trabalho mecânico a frio, ou elevar a dureza devido a precipitação de partículas de segunda fase na matriz.

Um tratamento térmico consiste basicamente em aquecer um determinado material, mantê-lo em uma dada temperatura durante um certo tempo, e em seguida, resfriálo sob uma taxa controlada, no qual, pode ser mais lento (dentro do próprio forno do tratamento térmico), moderado (ao ar parado ou forçado) e rápido (devido a imersão da amostra em água, salmoura ou óleo).

Tratamentos térmicos, como por exemplo, o de envelhecimento, é uma opção muito relevante para o ganho de resistência mecânica em ligas metálicas que não apresentam a transformação de fase em uma fase mais resistente após o tratamento térmico, como é o caso do alumínio e suas ligas.

Dentre as ligas de alumínio, as ligas da série $2 X X X$ e $7 X X X$, são as que têm suas propriedades mecânicas mais significativamente elevadas quando são submetidas a tratamentos térmicos adequados.

Dentre os tratamentos térmicos existentes para as ligas de alumínio, o tratamento térmico de solubilização é utilizado com a finalidade de solubilizar precipitados, formando uma matriz rica em soluto, e normalmente ocorre antes de um tratamento térmico de envelhecimento. O tratamento térmico de solubilização consiste em manter uma dada amostra por volta dos $500^{\circ} \mathrm{C}$, e fazer um resfriamento rápido, que geralmente é realizado em água.

Após o tratamento térmico, obtêm-se uma matriz alfa, rica em soluto, e tal resultado pode ser mais facilmente comprovado através do decaimento da dureza do material, e também através da redução do percentual da composição química dos precipitados (1).

As ligas de alumínio da série $7 \mathrm{XXX}$ apresentam como elementos de liga o zinco, cobre, magnésio, manganês e silício, e são bastante utilizadas principalmente na indústria aeronáutica devido sua baixa densidade aliada a relativa elevada resistência mecânica devido os tratamentos térmicos realizados.

O tratamento térmico -T7351, na liga de alumínio 7475 , tem como finalidade maximizar a resistência à corrosão em detrimento das propriedades mecânicas devido o superenvelhecimento desta liga. Tal tratamento térmico consiste em um conjunto de operações que engloba primeiramente um tratamento térmico de solubilização (T7 indica liga solubilizada e estabilizada), no qual é realizado a uma temperatura de encharque de $510^{\circ} \mathrm{C}$ (podendo ter uma variação máxima de $\pm 6^{\circ} \mathrm{C}$ ). Após ser atingido um determinando tempo de encharque, o material é retirado rapidamente do forno e resfriado até a temperatura ambiente por meio de uma imersão em água a temperatura ambiente. Logo após o tratamento térmico de solubilização é realizado um alívio de tensões por estiramento, para obter uma microestrutura diferenciada para a próxima etapa, no qual é o tratamento térmico de envelhecimento a fim de se ter um superenvelhecimento. Nesta etapa são realizados dois tratamentos térmicos distintos no material, cujo primeiro é conduzido durante 6 a 8 horas de encharque a uma temperatura de $107^{\circ} \mathrm{C}$, e logo em seguida é realizado um outro tratamento térmico de 24 a 30 horas a uma temperatura de $163^{\circ} \mathrm{C}(2,3)$. 
Para a liga de alumínio 7475-T7351 dependendo da espessura da chapa, são possíveis até 2 tratamentos térmicos de solubilização após o tratamento térmico T7351, e como a liga já foi solubilizada em uma etapa anterior, esta nova etapa de solubilização deve ser chamada de ressolubilização(2).

O principal foco do tratamento térmico de ressolubilização (TS) neste trabalho será de produzir uma microestrutura ressolubilizada, a fim de obter precipitados mais finos e uma matriz supersaturada (distinta da condição estabilizada com precipitados grosseiros oriundos da condição CR), bem como observar a cinética de precipitação natural da liga. Para este objetivo, serão realizados tratamentos térmicos de ressolubilização com distintos tempos (70, 80 e 90 minutos) a uma temperatura de $510^{\circ} \mathrm{C}$ em uma liga de alumínio $7475-T 7351 \mathrm{com} 12,5 \mathrm{~mm}$ de espessura. Como técnicas de caracterização foram utilizados o ensaio de dureza Vickers e Microscopia Óptica.

\section{MATERIAL E MÉTODOS}

Utilizou-se uma liga de alumínio de 7475 com um tratamento térmico prévio T7351, na forma de chapa laminada a quente com uma espessura inicial de $12,5 \mathrm{~mm}$ (esta condição será denominada de CR neste trabalho).

Com base na faixa de temperatura e tempos dos tratamentos térmicos de solubilização/ressolubilização adotados para a liga de alumínio 7475 com uma espessura aproximada de $12,5 \mathrm{~mm}^{(2,4)}$, para este trabalho foi utilizado uma temperatura de $510^{\circ} \mathrm{C}$ (com uma variação máxima de $+/-4^{\circ} \mathrm{C}$ ) e os tempos de encharque de 70, 80 e 90 minutos, sendo cada amostra originada destes tratamentos nomeadas de TS70, TS80 e TS90, respectivamente. Todas as amostras foram colocadas no interior do forno quando este estava a uma temperatura de $510^{\circ} \mathrm{C}$, e ao atingir o tempo de encharque estabelecido, asmesmas foram retiradase mergulhada em água a temperatura ambiente com agitação das mesmas. É importante salientar, que após os tratamentos térmicos, todas as amostras foram guardadas no interior de uma sala onde a temperatura variou de 21 a $26^{\circ} \mathrm{C}$.

Para a visualização da microestrutura das amostras, estas foram lixadas com lixas de carbeto de silício de granulometrias de 220 a 1200 mesh, e polidas com pasta de diamante de 6, 3 e $1 \mu \mathrm{m}$. Após o polimento, com intuito de revelar os contornos dos grãos, as amostras foram imersas em uma solução contendo $4 \%$ de $\mathrm{NaOH}$ e $96 \%$ de $\mathrm{H}_{2} \mathrm{O}$, em peso, durante aproximadamente 60 segundos, com subsequente imersão em Nital 5\% (5\% de Ácido Nítrico + 95\% de Álcool Etílico 98,9\% PA, ambos em volume) durante aproximadamente 3 segundos, logo em seguida as amostras foram lavadas com água corrente, álcool e secadas com jato de ar quente. Esta sequência (polimento/ataque) foi repetida 8 vezes em cada amostra. Foi utilizado um microscópio óptico do fabricante Olympus, modelo GX51, acoplado a uma câmera digital colorida (marca Olympus, modelo DP25), controlada pelo software de aquisição e análise de imagens OLYMPUS Analysis. As imagens foram registradas em posições associadas a $1 / 4$ e $1 / 2$ da espessura, com um menor aumento (200x) e maior aumento (1000x). Todas as imagens foram registradas após 168 horas (7 dias) do tratamento térmico de solubilização.

Para as análises de dureza Vickers, foi-se utilizado uma carga de $50 \mathrm{kgf}$, durante um tempo de permanência de 15 segundos (durômetro digital, fabricante EMCOTEST, modelo Duravision 300). Para esta análise as amostras foram lixadas em uma lixadeira rotativa manual com lixas de carbeto de silício de 220, 320, 500, 800, 1000, 
1200 e 2500 mesh. Após a etapa de lixamento as amostras foram lavadas sob água corrente, com álcool e secadas com jato de ar quente.

Para as amostras CR, TS70, TS80 e TS90 foram realizadas 5 medições em regiões associadas a $1 / 4,1 / 2$ e $3 / 4$ da espessura da chapa $(12,5 \mathrm{~mm})$. Nas amostras submetidas ao tratamento térmico de solubilização, as medições foram realizadas após exatamente 168 horas (7 dias) o tratamento térmico das amostras.

Em uma segunda amostra TS70, foram realizadas medições de dureza com o mesmo equipamento e carga, em regiões associadas a $1 / 4$ e $1 / 2$ da espessura da chapa após $1,2,3,4,5,6,7,8,9,10,24,48,72,96,125,173,505$ e 1945 horas do tratamento térmico de solubilização.

\section{RESULTADOS E DISCUSSÃO}

A Figura 1 apresenta um gráfico que ilustra a evolução da dureza Vickers após o tratamento térmico de ressolubilização com o tempo de encharque de 70 minutos (amostra TS70).

\section{Evolução da Dureza Vickers}

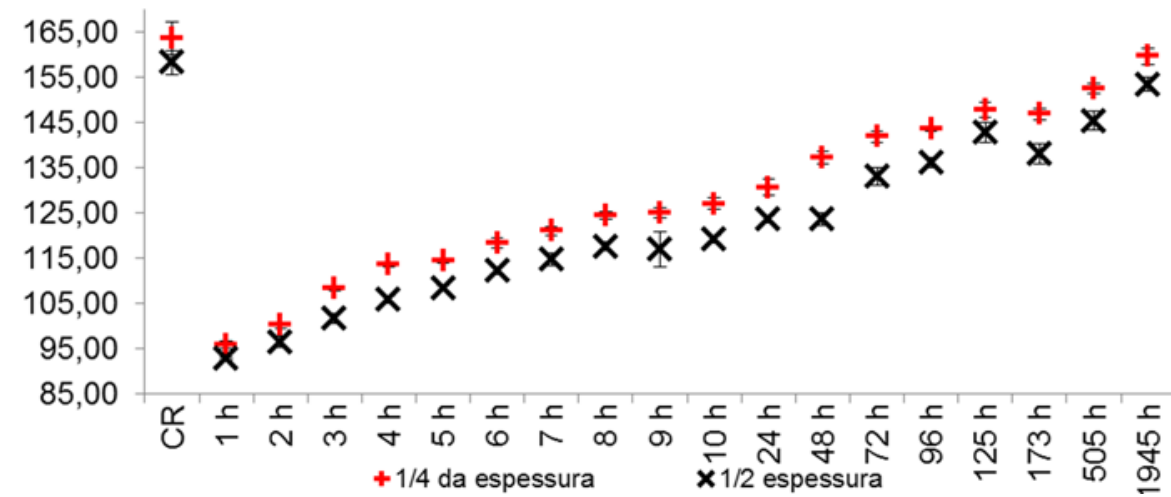

Figura 1. Evolução dadureza Vickers (carga de $50 \mathrm{~kg}$ ) após o tratamento térmico de ressolubilização com o tempo de encharque de 70 minutos.

Conforme observado na Figura 1, após 1 hora do tratamento térmico de solubilização da liga 7475-T7351, a dureza da amostra TS70 é de aproximadamente $94,35 \mathrm{HV}$ (média dos valores de dureza obtidos a $1 / 4$ e $1 / 2$ espessura), que representa $58,63 \%$ da dureza inicial da amostra. Outro fato também observado, é que o incremento da dureza é mais significativo nas primeiras 8 horas após o tratamento térmico, no qual atinge o valor médio (média entre medições a $1 / 4$ e $1 / 2$ espessura) de $121,00 \mathrm{HV}$, que representa $75,20 \%$ da dureza inicial.

Para tempos maiores do que 8 horas a dureza tende a aumentar com o passar do tempo após o tratamento térmico de ressolubilização, porém o incremento da dureza é menor quanto maior o tempo após o tratamento térmico de ressolubilização. Conforme as medidas realizadas neste estudo, obteve-se um valor de $159,60 \mathrm{HV}$ para $1 / 4$ da espessura e de $153,40 \mathrm{HV}$ para $1 / 2$ espessura após 1945 horas. Embora perto dos valores obtidos na amostra CR (163,60 para $1 / 4$ da espessura e 158,80 para $1 / 2$ espessura) é necessário realizar medições com tempos maiores após o tratamento térmico para verificar quando ocorre a estabilidade da dureza.

Este comportamento de incremento da dureza após um tratamento térmico de solubilização/resolubilização, é denominado de envelhecimento natural(2), que é evidenciado em algumas ligas de alumínio da série $7 \mathrm{XXX}{ }^{(2)}$, porém para a liga 7475 T7351 não foram encontrados registros na literatura que relatam tal comportamento, 
e também alguns autores citam a que condição solubilizada desta liga é estávelAs ligas que sofrem o envelhecimento natural, tal envelhecimento se completa e faz com que a dureza da liga torne estável em poucas horas, geralmente inferior a 48 horas.

Comparando entre si as médias dos valores de dureza medidos a $1 / 4$ e $1 / 2$ espessura, nota-se que até 2 horas após o tratamento térmico, a diferença entre estas regiões não é muito significativa, e que após 3 horas até 1945 horas, a diferença entre a dureza medidas nas regiões de $1 / 4$ e $1 / 2$ espessura é aproximadamente igual. Tal comportamento, indica uma possível diferença na segregação de soluto entre as regiões $1 / 2$ e $1 / 4$ da espessura, no qual já era esperado, devidoao material de início do estudo ser laminado a quente. Tal diferença de segregação pode ter influenciado de certo modo na cinética de precipitação após 0 tratamento térmico de ressolubilização.

Nas Figuras 2, 3, 4 e 5 são apresentadas as microestruturas em posições associadas a $1 / 4(a, b)$ e $1 / 2$ (c, d) espessura das amostras CR, TS70, TS80 e TS90, respectivamente, registradas com menor aumento, 200x (a, c) e maior aumento, 1000x (b, d). Nas figuras, "CG" indicam os contornos de grãos, "GE" grãos com coloração escura, "PG" precipitados grosseiros e "GC" grãos com coloração clara.

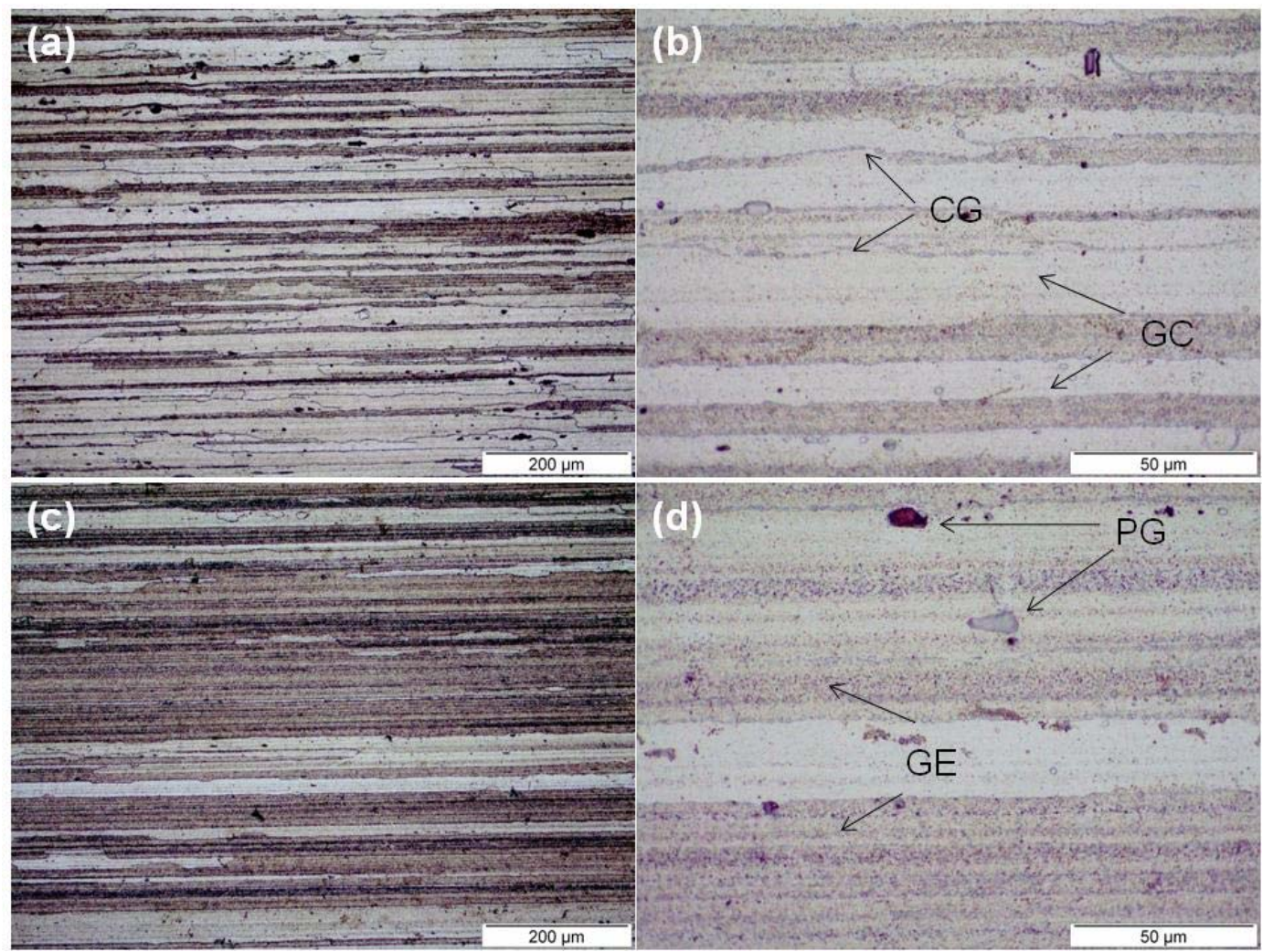

Figura 2. Microestrutura da amostra CR visualizada à $1 / 4$ da espessura ((a) e (b)) e $1 / 2$ espessura ((c) e (d)) registradas com menor aumento ((a) e (c)) e maior aumento ((b) e (d)). Direção de laminação, Microscópio Óptico, amostra com ataque. 

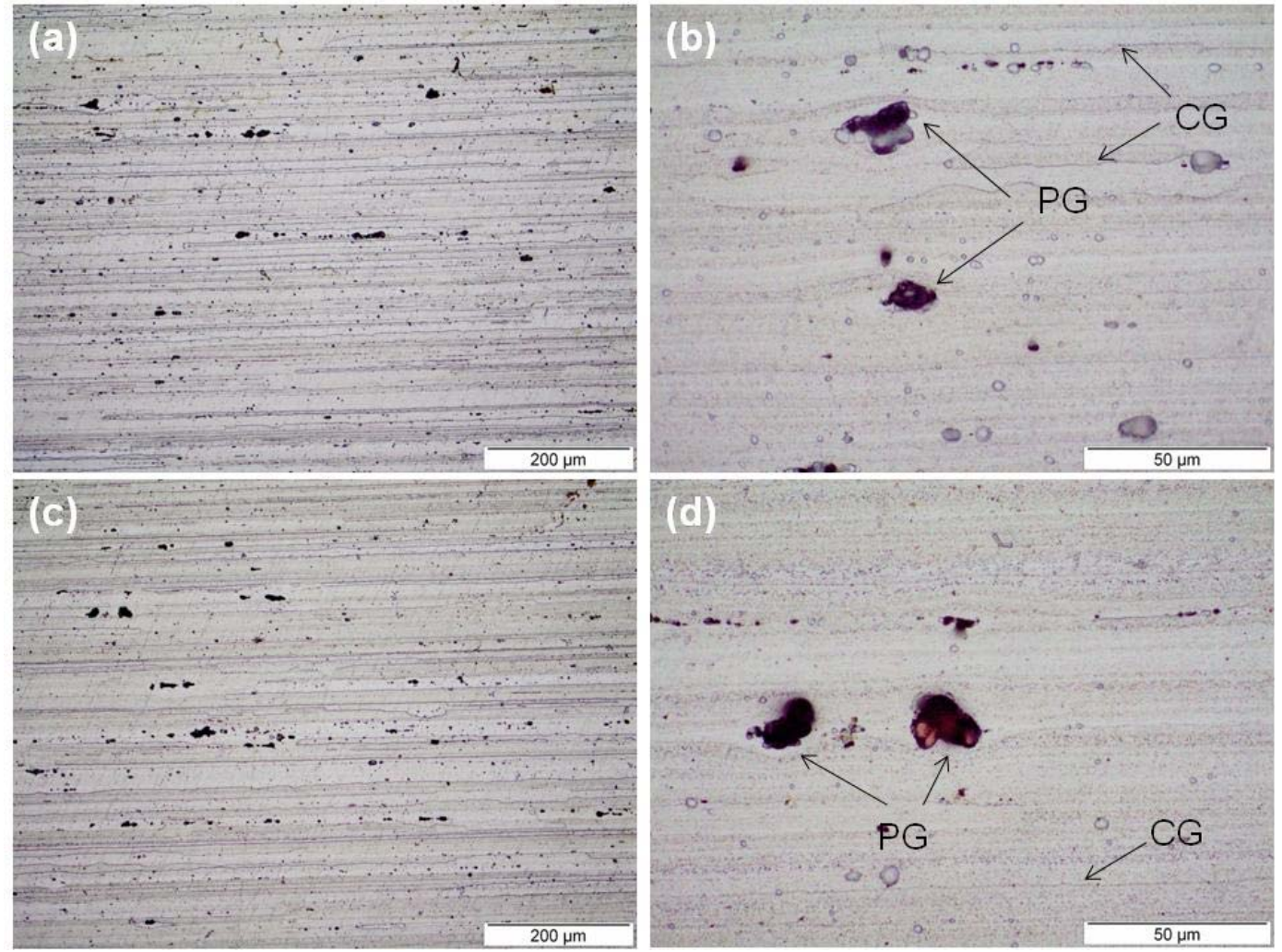

Figura 3. Microestrutura da amostra TS70 visualizada à $1 / 4$ da espessura ((a) e (b)) e $1 / 2$ espessura ((c) e (d)) registradas com menor aumento ((a) e (c)) e maior aumento ((b) e (d)). Direção de laminação, Microscópio Óptico, amostra com ataque.
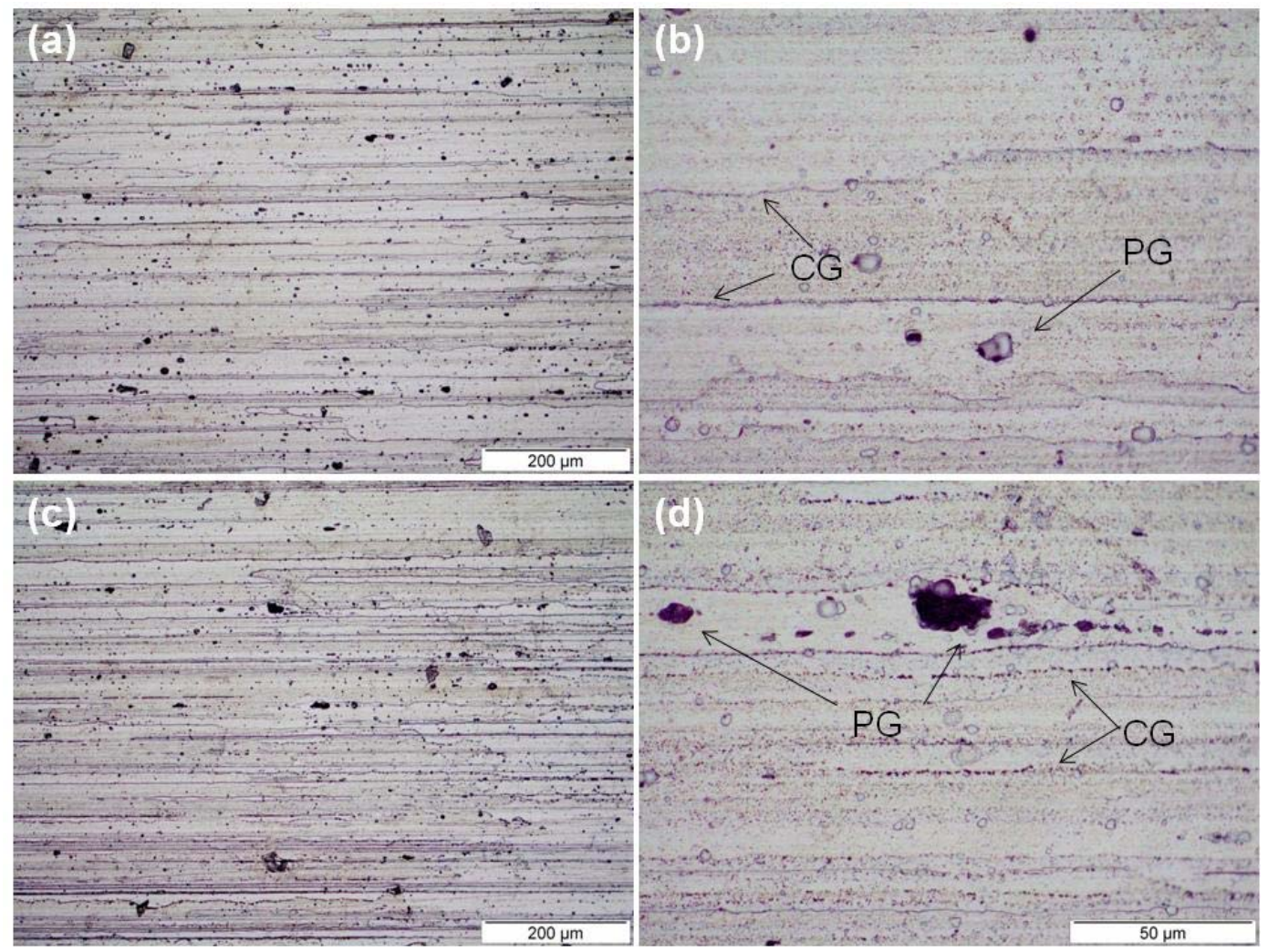

Figura 4. Microestrutura da amostra TS 80 visualizada à $1 / 4$ da espessura ((a) e (b)) e $1 / 2$ espessura ((c) e (d)) registradas com menor aumento ((a) e (c)) e maior aumento ((b) e (d)). Direção de laminação, Microscópio Óptico, amostra com ataque. 

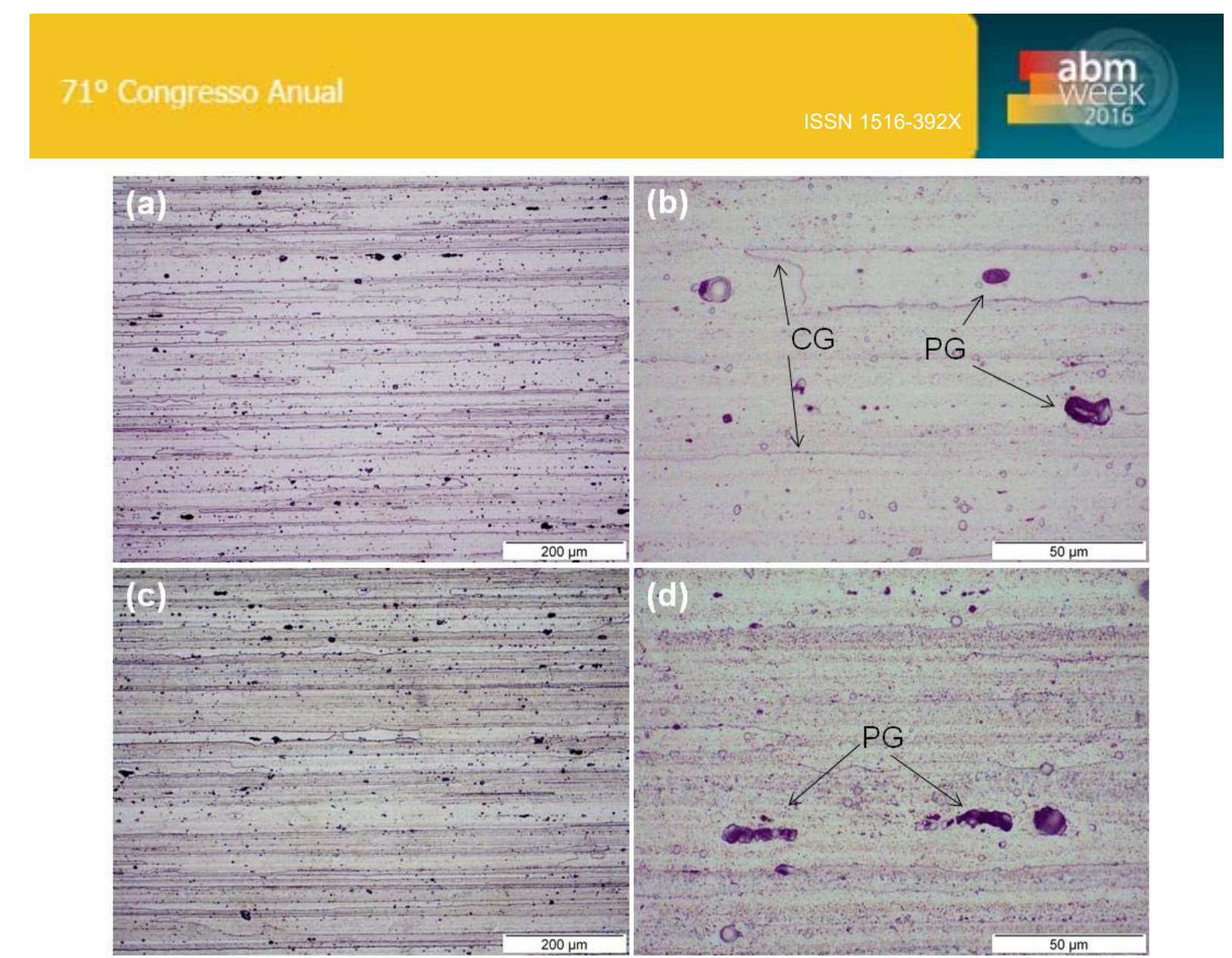

Figura 5. Microestrutura da amostra CR visualizada à $1 / 4$ da espessura ((a) e (b)) e $1 / 2$ espessura ((c) e (d)) registradas com menor aumento ((a) e (c)) e maior aumento ((b) e (d)). Direção de laminação, Microscópio Óptico, amostra com ataque.

De acordo com os detalhes microestruturais apresentados na Figura 2 pode-se observar que há uma coloração distinta dos grãos presentes na amostra $\mathrm{CR}$, onde observa-se grãos claros (indicado por "GC"), grãos escuros (indicado por "GE") e outros com uma coloração intermediária. Além de grãos com colorações distintas também se observa a presença de precipitados grosseiros, indicados por "PG", e de contornos de grãos mais facilmente visualizados no interior de grãos claros (indicado por "CG"). Outro fato também observado na Figura 2 é que os grãos são muitos grosseiros e alongados na direção de laminação.

Comparando as microestruturas obtidas da amostra $\mathrm{CR}$ em relação a região de visualização, ou seja, a $1 / 4$ e $1 / 2$ espessura, pode-se observar que as microestruturas obtidas a $1 / 2$ espessura tem maior fração volumétrica de grãos de coloração escura do que grãos de coloração clara, quando comparado com as regiões de $1 / 4$ da espessura.

De acordo com as Figuras 3, 4 e 5 referentes as amostras TS70, TS80 e TS90, respectivamente, pode-se observar que a mesma preparação utilizada para evidenciar os grãos de coloração clara e escura, bem como os contornos de grãos, da amostra CR (Figura 2) não foi tão efetivo. Possivelmente tal acontecimento para as amostras TS70, TS80 e TS90 pode estar associado a mudança da composição química da matriz, causada da dissolução parcial dos precipitados, e desta forma, a rota metalográfica adotada foi menos eficiente em revelar a microestrutura.

Outro fato também observado para as amostras TS70, TS80 e TS90 é que o perfil de grãos grosseiros alongados na direção de laminação evidenciados na amostra $\mathrm{CR}$, ainda se fazem presentes após o tratamento térmico de resolubilização. Também visualmente não se observa uma menor fração volumétrica dos precipitados existentes nas amostras TS70, TS80 e TS90 em comparação com a 
amostra CR. Esta constatação deve ser devido a limite de resolução da microscopia óptica e a possível dissolução e reprecipitação de precipitados de dimensão submicro a nanométrica.

Na Figura 6 é apresentada a evolução da dureza Vickers (HV) para as amostras CR, TS70, TS80 e TS90.

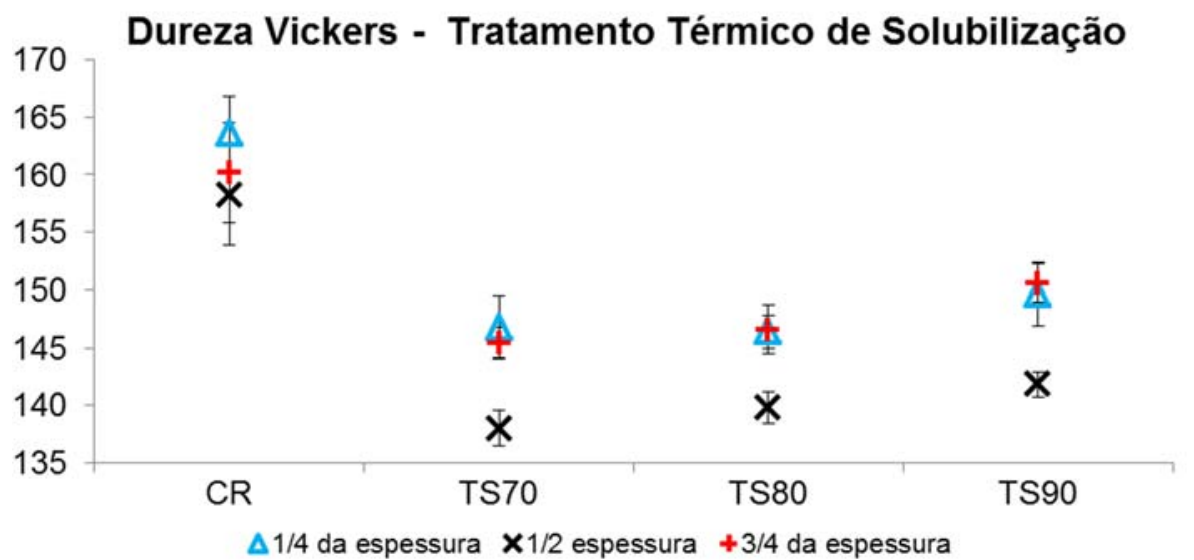

Figura 6. Dureza Vickers com uma carga de $50 \mathrm{~kg}$ das amostras TS70, TS80 e TS90.

De acordo com a Figura 6 é constatado que dentre as amostras TS70, TS80 e TS90, a que apresentou uma menor dureza média (média entre as medições a $1 / 4,1 / 2$ e $3 / 4$ da espessura) foi a amostra TS70, logo pode-se inferir que dentre os tempos utilizados o que apresenta melhores resultados de solubilização é o de 70 minutos.

Monteiro et al(2014) em seu trabalho, constataram uma relação entre a dureza Vickers e a composição química de precipitados de dimensão micrométrica(obtidos por MEV/EDS), para as ligas em estudo, quanto menor a composição química dos precipitados, devido a dissolução dos mesmos, menor era a dureza.

Constatar este tipo de comportamento, ou seja, relação entre dureza e composição química dos precipitados, através de análises realizadas por MEV / EDS em ligas que sofrem envelhecimento natural, se torna muito difícil, devido uma série de complicações experimentais, como por exemplo, demora por parte das análises, e até mesmo a garantia de acompanhar a evolução de um mesmo precipitado ou população de precipitados, durante várias horas após o tratamento térmico.

\section{CONCLUSÃO}

De acordo com o estudo realizado pode-se concluir que:

- a liga de alumínio 7475-T7351 após o tratamento térmico de ressolubilziação apresenta um envelhecimento natural, e esta liga demora pelo menos 1945 horas para se tornar estável após o tratamento térmico;

- de acordo com os valores de dureza obtidos, a amostra com o melhor tempo de ressolubilização foi a amostra TS70;

- não foi possível verificar uma aparente diferença de fração volumétrica dos precipitados, possivelmente devido ao uso da microscopia óptica,quando se compara as amostras CR, TS70, TS80 e TS90;

- a mesma rota de preparação metalográfica utilizada para a amostra CR não foi tão efetiva para as amostras TS70, TS80 e TS90, ou seja, a visualização dos contornos de grão bem como diferença da coloração dos precipitados, não é tão evidente nas amostras tratados como na amostra CR, no qual este comportamento pode estar associado a mudança de composição química da matriz. 


\section{Agradecimentos}

Os autores agradecem a CAPES pela bolsa de doutorado do autor Saulo Brinco Diniz e ao Instituto SENAI de Tecnologia - Solda, pela utilização do macrodurômetro digital EMCOTEST- Duravision 300 e microscópio óptico Olympus - GX51 / câmera digital colorida Olympus - DP25.

\section{REFERÊNCIAS}

1 Monteiro ,VM, Diniz SB, Meirelles BG, Silva LC, Paula AS. Microstructural and Mechanical Study of Aluminium Alloys Submitted to Distinct Soaking Times During Solution Heat Treatment. Tecnologia em Metalurgia, Materiais e Mineração. 2014; v. 4: 332-339.

2 ASM Handook. Heat Treating. ASM International: volume 4, 1991.

3 BRAGA APV. Análise de Ligas de Alumínio Aeronáuticas Conformadas por Jateamento com Granalhas - Caracterização e Previsão de Deformação. Dissertação de metrado: Escola Politécnica da Universidade de São Paulo, USP, São Paulo, 2011

4 ASM Handook.Properties and Selection: Nonferrous Alloys and Special-Purpose Materials. ASM International: volume 2, 1990. 